\title{
Impact of training program for attack accompanied by foot work after feint on development of performance level for boxing juniors
}

\section{Dr. Ahmed Kamal Abd El-Fatah Eid}

\section{- Introduction and research problem:}

Boxing is considered one of the individual sports inserted in the Olympics where participated countries compete for forty Olympics medals, so many of these countries provide all human and financial abilities for boxing to achieve the largest number of these medals, Abd El-Rahman Saif (2010), Ahmed Said (2012) have mentioned that to achieve winning and reaching high levels this requires efficiency of boxers for attack performance from long punch distance, also efficiency in all feint skills and foot work because they are the most important ways to confuse the competitor on the ring and this is through training in equal groups to join the boxer's level in competition and his level during training. (1:13)(3:12)

The research problem emerging through the researcher's observation during practicing boxing as a player and then as a coach, also following many republic championships for juniors, it becomes clear that most junior boxers during carrying out attack not preceded by some feint skills which depend on arm , trunk and foot, that aims at finding gaps in the competitor's defense through confusing his attention by these feint skills, If there are some junior boxers who perform feint before attack, he attacks after this feint from steadiness not through movement in which performing attack punches is at the same time of foot work towards the competitor, the researcher explains that concentration is on training on attack skills from steadiness and no care for attack skills accompanied by foot work and joining it with suitable feint skills before carrying it out, while the boxer who is good at attack accompanied by foot work after Feint this helps him to obstruct the probable counter attack form his competitor as a reaction to this attack and this is because attack accompanied by foot work causes stress and surprise to the competitor during carrying out, so this greatly obstructs the competitor's use of counter attack .

Besides, using one foot or both at the moment of attack helps to provide the boxer with power and speed needed for performing successful attack punches which are qualified with strength characterized with speed to achieve the largest number of points.

Hence, the researcher came up with designing a training program for some attack skills accompanied by foot work after Feint and know its effect on development of performance level for boxing juniors. 


\section{- Research Objective:}

- Designing a training program for some of the attack skills accompanied by foot work after Feint and Identifying its impact on development of performance level for boxing juniors.

- Research Hypothese:

- There are statistically significant differences between the pre and post measurements of the research sample in development of performance level for the post measurement.

- Research Terms:

- Attack Accompanied By Foot Work After Feint:

- It's the ability of junior boxer to give attack punches accompanied by foot work to the competitor after feint skill by using (arms - trunk - foot). (Procedural definition).

- Development Of Performance Level:

- The junior's ability to score the largest possible number of attack skills accompanied by foot work after Feint during the games to achieve the largest number of points. (Procedural definition).

- Research procedures:

- Research Method

The researcher chose the experimental method for its suitability to the study nature and objective, using the experimental design with pre and post measurements on one experimental group.

\section{- Research Sample}

The research sample was chosen intentionally form the juniors of Menoufia area boxers (under 17 years) and who were registered in the Egyptian Federation of Boxing, that consists of (20) junior boxers, they were divided to The basic study sample, that consists of (10) junior boxers to experiment the training program, and survey study sample, that consists of (10) junior boxers to calculate scientific coefficients for physical and skill tests used.

- Homogeneity Of The research Sample (Basic - survey) :

The researcher makes sure of equation of the research sample individual data, which consists of (20) junior Boxers, in variables (Age - Training Age - Height Weight), Table (1) shows that: 
Table (1)

The Homogeneity of the research sample in (Age - Training Age - Height - Weight) $\mathbf{n}=\mathbf{2 0}$

\begin{tabular}{c|c|c|c|c|c}
\hline \hline Variables & $\begin{array}{c}\text { Measure } \\
\text { unit }\end{array}$ & $\begin{array}{c}\text { Arithmetic } \\
\text { mean }\end{array}$ & $\begin{array}{c}\text { Standard } \\
\text { deviation }\end{array}$ & Median & Skewness \\
\hline \hline Age & month & 193.29 & 0.89 & 193.00 & 0.98 \\
\hline Training Age & month & 36.98 & 0.75 & 37.20 & -0.88 \\
\hline Height & cm & 166.34 & 5.14 & 164.98 & 0.79 \\
\hline Weight & Kg & 56.31 & 7.86 & 55.16 & 0.44 \\
\hline \hline
\end{tabular}

Table (1) shows that torsion modulus in the variables (Age - Training Age Height - Weight) was limited between $(-3,+3)$ which shows the homogeneity of the research sample in these variables.

\section{- Data collecting tools:}

- A form for recording the results of the attack accompanied by foot work after Feint for boxing juniors, (prepared by the researcher). (annex 1)

- A form to solicit the views of experts in the field to recognize attack skills accompanied by foot work, and Feint skills for boxing juniors. (annex 2), and determine the training program variables (annex 3), and determine the physical and skill Tests for boxing juniors. (annex 4)

\section{- Scientific coefficients for tests used}

- Test sincerity

The researcher calculated sincerity of distinction between two groups, one is not distinguished and it is outside the basic sample while the other is distinguished (surveyed), and each of them consisted of (5) boxers. 
Table (2)

Indication of the differences between the two groups (distinguished and nonDistinguished) in the tests of the research

$\mathrm{n} 1=\mathrm{n} 2=5$

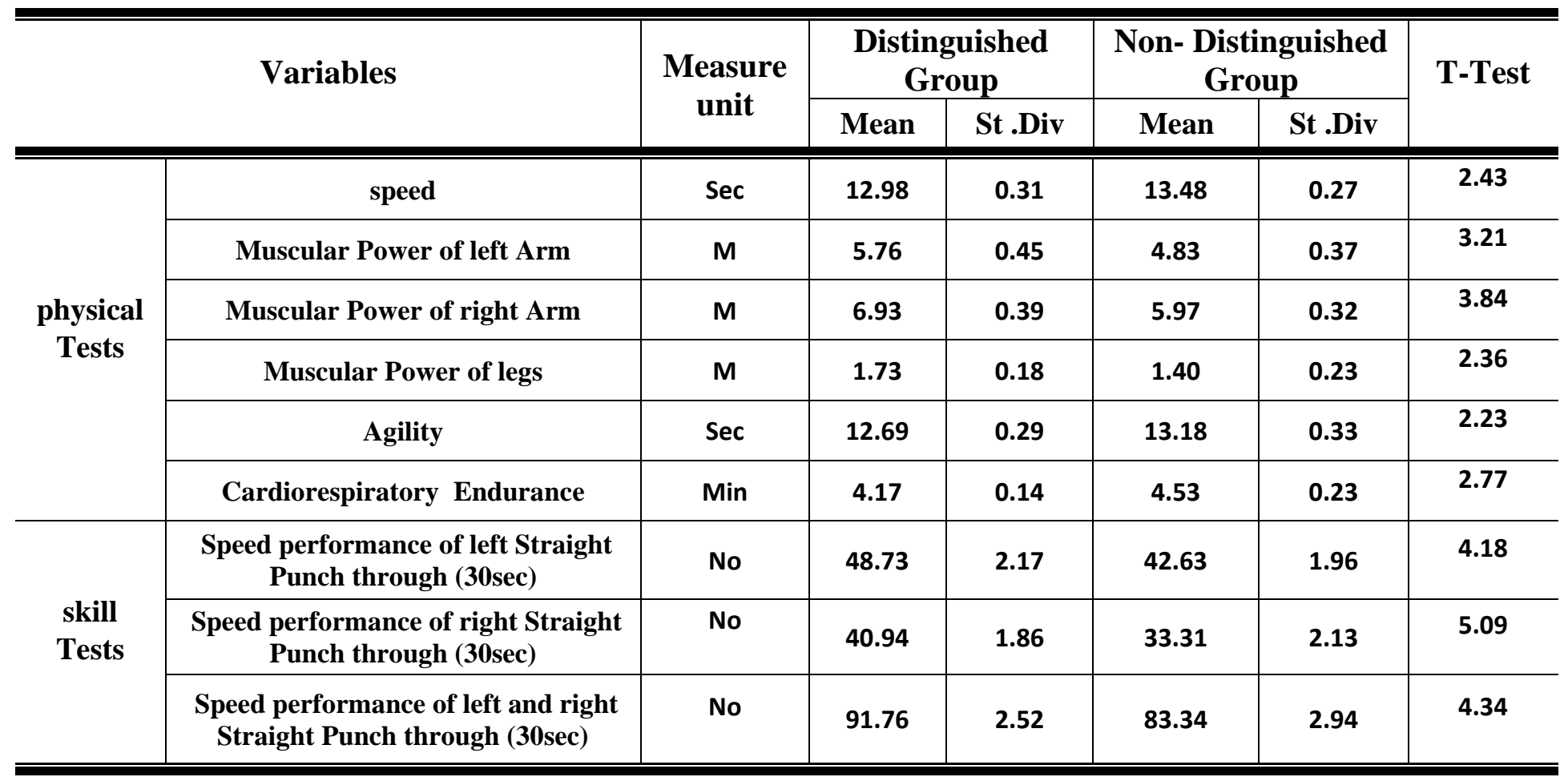

"T" value from the table at $(0.05)=1.860$

Table (2) shows the presence of statistically significant differences in favor of distinguished group, which refers to the sincerity of the tests.

- Tests stability

The researcher calculated tests stability using re-testing on the surveyed sample of (5) Boxers, after a week as interval between the two applications. 
Table (3)

The arithmetic mean, standard deviation and correlation coefficient between the first application and the second application of physical and skill tests for the surveyed sample in the research $\quad n=(5)$

\begin{tabular}{|c|c|c|c|c|c|c|c|}
\hline \multirow{2}{*}{\multicolumn{2}{|c|}{ Variables }} & \multirow{2}{*}{$\begin{array}{c}\text { Measure } \\
\text { unit }\end{array}$} & \multicolumn{2}{|c|}{ First application } & \multicolumn{2}{|c|}{ Second application } & \multirow{2}{*}{$\mathbf{R}$} \\
\hline & & & Mean & St .Div & Mean & St .Div & \\
\hline \multirow{6}{*}{$\begin{array}{c}\text { physical } \\
\text { Tests }\end{array}$} & speed & Sec & 12.98 & 0.31 & 13.14 & 0.26 & $0.92^{*}$ \\
\hline & Muscular Power of left Arm & M & 5.76 & 0.45 & 5.83 & 0.56 & $0.88^{*}$ \\
\hline & Muscular Power of right Arm & $\mathbf{M}$ & 6.93 & 0.39 & 6.98 & 0.47 & $0.89 *$ \\
\hline & Muscular Power of legs & M & 1.73 & 0.18 & 1.71 & 0.25 & $0.94^{*}$ \\
\hline & Agility & Sec & 12.69 & 0.29 & 12.57 & 0.48 & $0.93^{*}$ \\
\hline & Cardiorespiratory Endurance & Min & 4.17 & 0.14 & 4.23 & 0.17 & $0.91^{*}$ \\
\hline \multirow{3}{*}{$\begin{array}{l}\text { skill } \\
\text { Tests }\end{array}$} & $\begin{array}{l}\text { Speed performance of left Straight } \\
\text { Punch through (30sec) }\end{array}$ & No & 48.73 & 2.17 & 49.81 & 1.95 & $0.90^{*}$ \\
\hline & $\begin{array}{l}\text { Speed performance of right Straight } \\
\text { Punch through (30sec) }\end{array}$ & No & 40.94 & 1.86 & 41.53 & 2.05 & $0.92^{*}$ \\
\hline & $\begin{array}{l}\text { Speed performance of left and right } \\
\text { Straight Punch through }(30 \mathrm{sec})\end{array}$ & No & 91.76 & 2.52 & 93.25 & 2.11 & $0.89 *$ \\
\hline
\end{tabular}

The tabulated value of " $R$ " is $(0.729)$ at significance level $(0.05)$

As reflected in table (3), the value of calculated " $R$ " is higher than the tabulated " $\mathrm{R}$ " which indicates the stability of tests.

- Homogeneity of the experimental research sample in variables (physical-skill) for boxing juniors:

The researcher makes sure of equation of the experimental research sample individual data, which consists of (10), junior Boxers, in variables (physical - skill), Table (4) shows that: 
Table (4)

The homogeneity of the experimental research sample in the variables (physical-skill) for boxing juniors $\quad \mathrm{n}=10$

\begin{tabular}{|c|c|c|c|c|c|c|}
\hline \multicolumn{2}{|r|}{ Variables } & Measure & Arithmetic & Standard & Median & Skewness \\
\hline \multirow{6}{*}{$\begin{array}{c}\text { physical } \\
\text { Tests }\end{array}$} & speed & Sec & 12.86 & 0.37 & 12.79 & 0.57 \\
\hline & Muscular Power of left Arm & M & 5.78 & 0.34 & 5.69 & 0.79 \\
\hline & Muscular Power of right Arm & $\mathbf{M}$ & 6.91 & 0.28 & 6.85 & 0.64 \\
\hline & Muscular Power of legs & $\mathbf{M}$ & 1.75 & 0.13 & 1.73 & 0.46 \\
\hline & Agility & Sec & 12.73 & 0.25 & 12.69 & 0.48 \\
\hline & Cardiorespiratory Endurance & Min & 4.19 & 0.19 & 4.22 & -0.47 \\
\hline \multirow{3}{*}{$\begin{array}{l}\text { skill } \\
\text { Tests }\end{array}$} & $\begin{array}{l}\text { Speed performance of left Straight } \\
\text { Punch through (30sec) }\end{array}$ & No & 48.91 & 2.43 & 49.30 & -0.48 \\
\hline & $\begin{array}{c}\text { Speed performance of right Straight } \\
\text { Punch through }(30 \mathrm{sec})\end{array}$ & No & 40.87 & 2.11 & 41.15 & -0.40 \\
\hline & $\begin{array}{l}\text { Speed performance of left and right } \\
\text { Straight Punch through }(30 \mathrm{sec})\end{array}$ & No & 92.52 & 2.32 & 93.28 & -0.98 \\
\hline
\end{tabular}

Table (4) shows that the torsion modulus in the variables (physical-skill) was limited between $(-3,+3)$ which shows the homogeneity of the experimental research sample in these variables.

- The basis of designing a training programs development

- The training program should suit the established objectives.

- The training program and its contents should suit the age range of the chosen sample.

- Taking into account the principles and foundations of training while designing the training program.

- Program flexibility and its ability to be modified.

- The regularity and continuity in practicing the training program to get the desired benefit.

- The determinants of the training program:

- The period of implementation of the program

The application period of the program has been defined to be (12 weeks) at (36) training units, and every week include (3) training units, the unit duration is (90minutes). (annex 5) 


\section{- Determination of the attack skills accompanied by foot work:}

Determining (6) attack skills accompanied by foot work stuitable for age through skill to (6) experts (annex 8) and putting show them in the proposed training program:

- Attack with a left straight punch to the head accompanied by a half step with the front foot.

- Attack with a right straight punch to the head accompanied by a half step with the front foot.

- Attack with a left straight punch to the head accompanied by a half step with the front foot followed by right straight punch to the head accompanied by a half step with the back foot.

- Attack with a right straight punch to the head accompanied by a half step with the front foot followed by left straight punch to the head accompanied by a half step with the back foot.

- Attack with a left straight punch to the head accompanied by a half step with the front foot followed by right straight punch to the head accompanied by a half step with the back foot followed by left straight punch to the head accompanied by a half step with the front foot.

- Attack with a right straight punch to the head accompanied by a half step with the front foot followed by left straight punch to the head accompanied by a half step with the back foot followed by right straight punch to the head accompanied by a half step with the front foot.

\section{- Determination of the Feint skills:}

Determining (6) feint skills stuitable for age through skill to (6) experts (annex 8) and putting show them in the proposed training program to join them with attack accompanied by foot work:

- Feint by weak punch.

- Feint by uncompleted punch.

- Feint by trunk forwards.

- Feint by trunk forwards towards the left.

- Feint by trunk forwards towards the right.

- Feint by a half step forwards with the front foot.

\section{- Training methods used}

The experts had agreed on using the periodic training methods (Low intensity high intensity). 


\section{- Determination of the intensity of training loads:}

The intensity of training loads for attack skills accompanied by foot work after Feint was (50\% : 95\%), and Heart rate (139: 197) pulse/min, and Rationing of training loads using Heart Rate by applying the following equation:

Target Heart Rate $=$

Resting heart rate $+[$ Training ratiox(Maximum heart rate - Resting heart rate)/100] Where:

- Maximum pulse rate $=220-$ age $=\ldots$ Pulse $/ \mathrm{min}$

- The reserves of the maximum rate of the pulse $=$ Maximum pulse rate - pulse rate at rest $=\ldots$. Pulse/min $(2: 235)$

\section{- Rationing of training loads:}

- The average age of the sample (16 years).

- Average pulse rate at rest for the sample (74) pulse/min.

- Maximum pulse rate $=220$ - average age . Maximum pulse rate $=220-16=204 \mathrm{pulse} / \mathrm{min}$

- The reserves of pulse $=$ Maximum pulse rate - pulse rate at rest The reserves of pulse $=204-74=130 \mathrm{pulse} / \mathrm{min}$.

- Rationing of training loads by using pulse rate:

- (Maximum load), percentage 90:100 \% , Pulse rate 191:204 pulse/min.

- (High load) , percentage 75:89\% , Pulse rate 171:190 pulse/min.

- (Moderate load) , percentage 50:74 \% , Pulse rate 139:170 pulse/min.

\section{- Pre - measurement:}

The researcher conducted the pre-measurement for experimental research sample on Saturday 2/1/2016, to recognize development of performance level, through holding experimental games between the experimental boxers group, and recording the experimental games, then show it to an expert to record the repetition of attack skills accompanied by foot work after Feint, through a form for recording the results.

\section{- Applying the proposed training program:}

The researcher applied the proposed training program on experimental research sample for (12 weeks) at (36) training units from Sunday 3/1/2016 to Thursday 24/3/2016.

\section{- Post - measurement:}

The researcher conduct the post-measurement for experimental research sample on Friday 25/3/2016, to recognize of development of performance level, through holding experimental games between the experimental boxers group, and recording the experimental games, then show it to an expert to record the repetition of attack 
skills accompanied by foot work after Feint, through a form for recording the results.

- Statistical processing:

The researcher has used the following statistical processes in this study: Arithmetic mean - The standard deviation -Median - Skewness - Correlation coefficient $-\mathrm{T}$ test.

\section{- Presentation and discussion of the results:}

Table (5)

Indication of the differences between the two measurements (Pre and Post) of the experimental group in the development of performance level. $\quad \mathrm{N}=(10)$

\begin{tabular}{|c|c|c|c|c|c|}
\hline \multirow[t]{2}{*}{ Research variables } & \multicolumn{2}{|c|}{$\begin{array}{c}\text { Pre - } \\
\text { measurement }\end{array}$} & \multicolumn{2}{|c|}{$\begin{array}{c}\text { Post - } \\
\text { measurement }\end{array}$} & \multirow[t]{2}{*}{$\mathbf{T}$} \\
\hline & Mean & St .Div & Mean & St .Div & \\
\hline $\begin{array}{l}\text { Attack accompanied by foot work after Feint } \\
\text { by weak punch. }\end{array}$ & 9.0 & 0.435 & 3.1 & 1.759 & $3.642 *$ \\
\hline $\begin{array}{l}\text { Attack accompanied by foot work after Feint } \\
\text { by uncompleted punch. }\end{array}$ & 6.0 & 0.663 & 2.7 & 1.436 & $3.985 *$ \\
\hline $\begin{array}{l}\text { Attack accompanied by foot work after Feint } \\
\text { by trunk forwards. }\end{array}$ & 4.0 & 0.489 & 2.2 & 2.064 & $2.546 *$ \\
\hline $\begin{array}{l}\text { Attack accompanied by foot work after Feint } \\
\text { by trunk forwards towards the left. }\end{array}$ & 2.0 & 0.40 & 1.3 & 1.027 & $2.997^{*}$ \\
\hline $\begin{array}{l}\text { Attack accompanied by foot work after Feint } \\
\text { by trunk forwards towards the right. }\end{array}$ & 3.0 & 0.468 & 1.5 & 1.163 & $2.871 *$ \\
\hline $\begin{array}{l}\text { Attack accompanied by foot work after Feint } \\
\text { by a half step forwards with the front foot. }\end{array}$ & 5.0 & 0.671 & 2.4 & 1.519 & $3.436^{*}$ \\
\hline
\end{tabular}

The tabulated value of " $T$ " (1.833) at significance level (0.05)

Table (5) shows the presence of statistically significant differences at the level (0.05) between pre and post measurements for the experimental group in favor of post measurements in attack skills accompanied by foot work after Feint, where the calculated " $T$ " value is higher than the tabulated value of " $T$ " for all variables:

Skill of (attack accompanied by foot work after Feint by weak punch), where the calculated "T" value is (3.642), (attack accompanied by foot work after Feint by uncompleted punch), where the calculated " $T$ " value is (3.985), (attack accompanied by foot work after Feint by trunk forwards), where the calculated " $T$ " value is (2.546), (attack accompanied by foot work after Feint by trunk forwards towards the right), where the calculated "T" value is (2.997), (attack accompanied 
by foot work after Feint by trunk forwards towards the left), where the calculated "T" value is (2.871), ), (attack accompanied by foot work after Feint by a half step forwards with the front foot), where the calculated " $T$ " value is (3.436), the researcher attribute this result to the training program containing attack skills accompanied by foot work after Feint which was applied on the experimental group with the scientific way according to limited time program, this helps junior boxers to acquire self confidence and gives them the ability to completely benefit from the performance of attack skills accompanied by foot work after Feint, has a positive effect on their performance level, and this agree with each of Tomas (2001)(9), Samy Moheb (2005)(7), Diaa Al-azab, Mahmoud Hussein (2006)(4) ,Yaser El-warakey (2007)(12),Ahmed Said (2012)(3), they mention that high level for boxers means they have the ability to join different kinds of feint and attack skills and foot movements, also the boxers who depend on the speed of foot movement through their attack this enables them to achieve the aim from attack where the good use of feet may be a source of winning through controlling the competitor and quick moving to attack without losing body balance.

Also Takred (1990)(8), Abd El-aziz Ghonam (1995)(6), Verlag (1996)(10), Yahia El-hawey (2000)(11), Gursoy (2009)(5) mention that those who are responsible for education affairs and training boxers must choose the attack planning methods that suit the abilities of boxers to achieve winning and reaching high levels.

\section{- Conclusions}

In light of the objectives and the results of this research, , the researcher reached the following conclusions:

- There are statistically significant differences at the level (0.05) between pre and post measurements for the experimental group in performance of attack skills accompanied by foot work after Feint, in favor of post measurements.

- The proposed training program leads to development of performance level for boxing juniors, through their depending on attack skills accompanied by foot work after Feint.

\section{- Recommendations}

- The coaches must take care of attack skills accompanied by foot work after Feint and training junior boxers on them to achieve reaching high levels.

- Holding meetings to attract the coaches attention to the importance of attack skills accompanied by foot work after Feint and their effect on the results of the matches.

- Directing the steps of carring out this training program to the coaches to design similar programs for different ages. 


\section{References}

1 Abd El-Rahman Saif

2 Abu El -Ela Abd El -Fattah, Ahmed Nasr El- din

3 Ahmed Said

4 Diaa El-Din Alazab , Mahmoud Hussein

5 Gursoy

6 Mohamed Abd ElAziz

7 Samy Moheb

8 Takrid

9 Tomas

10 Verlag

11 Yahia El-Hawy

12 Yaser El-waraky
(2010) Biochemical changes of continuous and interval training for boxers, Monchaat Al-Maaref, Alexandria.

(2003) Fitness Physiology, Dar of the Arab Thought, Cairo.

(2012) Ranges of using attack punch skills (individual, pair, group punches) and their defences for boxers taking part in Olympics in London (2012) published research, scientific Journal, Faculty of Physical Education for Boys, Helwan University. (2006) Analytical Study of the Punching Schools' Results at Olympic Tournaments in (Atlanta 1996 - Sydney 2000 Athena 2004) published research, Journal of Physical and Sports Sciences, Faculty of Physical Education, University of Menoufia.

(2009) Effects of left or right hand Preference on the success of boxers in Turkey.

(1995) Analytical Study of the Effective of Attack's Plans and defense of the Arabic Boxer, published research, Journal of faculty of physical education, Tanta University.

(2005)The entry to modern boxing, shagret Eldor library in mansoura.

(1990) boxing for boys Bulgaria.

(2001) technique of attack of the best amateur boxers of the world and Europe.

(1996) methods of training - boxing, teaches the c.v. mostly company saint Louis.

(2000) Boxing (Theoretical Bases - Practical Applications) Al-Aziz Library, Zagazig.

(2007) Analytical study for attack accompanied by foot work in the Olympics in Athena (2004), published research, Journal of Physical and Sports Sciences, Faculty of Physical Education, University of Menoufia 